University of Nebraska - Lincoln

DigitalCommons@University of Nebraska - Lincoln

Biological Systems Engineering: Papers and

Publications

Biological Systems Engineering

2005

\title{
Extraction of Lipids from Grain Sorghum DDG
}

L. Wang

University of Nebraska-Lincoln

Curtis L. Weller

University of Nebraska-Lincoln, cweller1@unl.edu

K. T. Hwang

Chonbuk National University

Follow this and additional works at: https://digitalcommons.unl.edu/biosysengfacpub

Part of the Biological Engineering Commons

Wang, L.; Weller, Curtis L.; and Hwang, K. T., "Extraction of Lipids from Grain Sorghum DDG" (2005).

Biological Systems Engineering: Papers and Publications. 96.

https://digitalcommons.unl.edu/biosysengfacpub/96

This Article is brought to you for free and open access by the Biological Systems Engineering at DigitalCommons@University of Nebraska - Lincoln. It has been accepted for inclusion in Biological Systems Engineering: Papers and Publications by an authorized administrator of DigitalCommons@University of Nebraska Lincoln. 


\title{
EXTRACTION OF LIPIDS FROM GRAIN SORGHUM DDG
}

\author{
L. Wang, C. L. Weller, K. T. Hwang
}

\begin{abstract}
Soxhlet and recirculated solvent extraction methods were used to extract lipid materials from grain sorghum DDG. The lipid content in DDG with a moisture content of $6.7 \%$ (dry basis) was as high as $9.32 \%$ of the dried DDG as determined by Soxhlet extraction with n-hexane. There was a slight increase in the lipid yield from $9.21 \%$ to $9.68 \%$ when the moisture contents increased from $2.1 \%$ to $17.4 \%$ (d.b.). Thin-layer chromatography (TLC) analysis showed that the sorghum lipids were composed of triacylglycerols, fatty acids, fatty alcohols, fatty aldehydes, free sterols, wax esters, and steryl esters. A bench-scale recirculated extraction system was used to investigate the extractability of lipid materials from the DDG under various experimental conditions including solvent to solid ratio $(2: 1$ to $5: 1)$, extraction temperature $\left(45^{\circ} \mathrm{C}, 55^{\circ} \mathrm{C}, 68^{\circ} \mathrm{C}\right)$, and extraction time ( 1 to $6 \mathrm{~h}$ ). The extractability of DDG lipid ranged from $70.3 \%$ to $94.5 \%$. At extraction temperatures near the boiling point of n-hexane, a solvent to solid ratio of 3:1, and an extraction time of 4 h achieved the maximum lipid yield. There was no apparent increase in the extraction yield with further increase of the solvent to solid ratio or extraction time.
\end{abstract}

Keywords. Extraction kinetics, Solvent extraction, Sorghum DDG, Sorghum lipids.

$\mathrm{D}$ ry-grind ethanol production continues to expand in the United States. More than 1.3 million metric tons of grain sorghum are used annually to produce ethanol, and the number of tons used is expected to increase in the future. Approximately $8.2 \mathrm{~kg}$ of dry residual in the form of distillers dried grains (DDG) remains from each $25 \mathrm{~kg}$ of grain sorghum used to produce ethanol. The DDG is sold solely as animal feed. Grain sorghum contains considerable amounts of lipid materials, including longchained fatty acids, fatty aldehydes, fatty alcohols (policosonols), triacylglycerols, and other valuable components such as phytosterols, tocols, and diacylglycerols (Hwang et al., 2002a, 2002b, 2002c; Singh et al., 2003). There is an increasing interest in the components of sorghum lipid such as sterols, tocopherols, and unsaturated fatty acids, as they may play a preventive role in many diseases (Singh et al., 2003). The economic value of sorghum DDG would likely increase if its lipid materials were extracted and further refined to concentrate fatty acids, fatty aldehydes, policosonols, phytosterols, tocols, and diacylglycerols.

Extraction techniques have been developed to obtain valuable commercial natural products with wide applications in the food, cosmetic, and pharmaceutical industries. Solvent

Article was submitted for review in July 2005; approved for publication by the Food \& Process Engineering Institute Division of ASABE in September 2005. Presented at the 2005 ASAE Annual Meeting as Paper No. 057054.

A contribution of the University of Nebraska Agricultural Research Division, Lincoln, Nebraska, Journal Series No. 14650.

The authors are Lijun Wang, ASABE Member Engineer, Research Assistant Professor, and Curtis L. Weller, ASABE Member Engineer, Professor, Department of Biological Systems Engineering, University of Nebraska-Lincoln, Lincoln, Nebraska; and Keum Taek Hwang, Professor, Department of Food Science and Human Nutrition, and Center for Healthcare Technology Development, Chonbuk National University, Jeonju, Korea. Corresponding author: Curtis L. Weller, Department of Biological Systems Engineering, 210 L. W. Chase Hall, University of Nebraska-Lincoln, Lincoln, NE 68583-0726; phone: 402-472-9337; fax: 402-472-6338; e-mail: cweller1@unl.edu. extraction of solid materials is commonly known as solid-liquid extraction or leaching. The solid-solvent extraction of natural products from plant matrices is based on the choice of solvents such as hexane (Zarnowski and Suzuki, 2004) and supercritical $\mathrm{CO}_{2}$ (Lang and Wai, 2001) coupled with the use of heating and/or agitation methods such as microwave heating (Kaufmann and Christen, 2002) or ultrasound (Vinatoru, 2001) to enhance the extraction. Among the various solid-solvent extraction techniques, the Soxhlet extraction method has been the main reference against which the performance of other leaching methods is compared (Luque de Castro and Garcia-Ayuso, 1998).

Performance of solid-solvent extraction depends on the selection of solvents, characteristics of solids, and operating conditions. A suitable extracting solvent should be selected for the extraction of targeted natural products. Different solvents will yield different extracts and extract compositions. The most widely used solvent to extract edible oils or lipids from plant sources is n-hexane due to its high oil solubility and ease of recovery (Zarnowski and Suzuki, 2004). Although n-hexane has been criticized for its environmental unfriendliness, solid-hexane extraction of lipids is still a standard technique and a popular reference for evaluating the performance of other solid-solvent extraction methods such as supercritical $\mathrm{CO}_{2}$ extraction.

However, no publication has been found that quantifies the contents and profiles lipids in sorghum DDG. For commercial use of sorghum DDG lipids, it is essential to investigate the effects of DDG characteristics and operating conditions of solid-solvent extraction on the extractability (i.e., percent ratio of extracted mass of lipids per mass of dried DDG to the total lipid content in the DDG as determined by Soxhlet extraction) of sorghum DDG lipids. In this study, the total lipid contents of sorghum DDG were first quantified using Soxhlet extraction with hexane. The compositions in the extracted lipids were determined using TLC. Experiments were further carried out on a bench-scale recirculated extraction system to investigate the effects of operational parameters of solid-solvent extraction such as time, tempera- 
ture, and solvent to solid ratios on the extractability of sorghum lipids.

\section{Materials AND Methods SORGHUM DDG AND REAGENTS}

Cultivar variations in sorghum source may lead to some difference in lipid contents and profiles (Maestri et al., 1996). Sorghum DDG used in this research was obtained from an ethanol production facility, U.S. Energy Partners (Russell, Kansas), that had been processing mixed commercial grain sorghum hybrids. Particle size distribution in the DDG was measured using a sieve shaker (Ro-Tap, W.S. Tyler, Cleveland, Ohio) equipped with six sieves (U.S. standard sieve opening: $1.7,1.4,1.18,0.85,0.5$, and $0.106 \mathrm{~mm}$ ) and a pan. The moisture content of the DDG was measured using a moisture analyzer at a chamber temperature of $105^{\circ} \mathrm{C}$ (HG 53 moisture analyzer, Mettler-Toledo $\mathrm{GmbH}$, Laboratory and Weighing Technologies, Greifensee, Switzerland). As ash particles in the DDG would increase the difficulty of downstream filtration, ash particles were removed from the unsieved DDG using a sieve (pore size: $106 \mu \mathrm{m}$ ) before extraction. The sorghum DDG was stored in a covered $20 \mathrm{~L}$ plastic bucket in a commercial freezer at $-12^{\circ} \mathrm{C}$ until needed for experiments. The measurements of particle size distribution and moisture content of DDG were carried out in triplicate.

Silica gel TLC plates (general purpose, $20 \times 20 \mathrm{~cm}$, particle size: $250 \mu \mathrm{m}$ ) were purchased from Aldrich Chemical Co. (Milwaukee, Wisc.). Standards for TLC analysis were purchased from Acros (Somerville, N.J.). The n-hexane (EM Science industrial grade) was purchased from Fisher Scientific (Pittsburgh, Pa.).

\section{SoXHLET EXTRaCtion}

A Soxhlet extractor (Foss Tecator Soxtec HT 6, Fisher Scientific, Pittsburgh, Pa.) was used to determine the total lipid contents in the DDG. For this, a $5 \mathrm{~g}$ DDG sample was placed in a single-thickness cellulose thimble $(26 \mathrm{~mm}$ I.D. $\times$ $60 \mathrm{~mm}$ length, $2 \mathrm{~mm}$ thickness, Whatman International, Ltd.,
Maidstone, U.K.), which was then transferred to the Soxhlet extractor. Each extraction cup was weighed and filled with $50 \mathrm{~mL}$ of hexane to collect the lipid. The solvent in each cup was refluxed in the Soxhlet extractor from 0.5 to $12 \mathrm{~h}$, depending on the time of study. The extracted lipid in each of the cups was placed in a convection air oven set at $60^{\circ} \mathrm{C}$ to remove residual hexane. The mass of each of the cups was monitored until it reached a constant value. The mass of extracted lipid was the mass difference of each cup after drying and before extraction. Lipid content or yield was determined from the mass of extracted lipid divided by the initial dry mass of grain sorghum DDG. The lipids were removed and placed in sealed glass bottles. All Soxhlet extractions were carried out in triplicate.

\section{Recirculated Solvent Extraction}

A bench-scale extractor, as constructed by Schmidt (2002) and shown in figure 1, was used to extract the lipids from the DDG samples. The extractor consisted of two major cylindrical vessels, with one serving as the solvent reservoir and the other as the extraction chamber. The vessels had outer jackets in which hot water was circulated to maintain a consistent temperature throughout the extraction. The hot water was supplied to the vessels from a round-bottomed flask on a mantle heater with a temperature controller. A peristaltic laboratory pump (MasterFlex model 7520-00, Cole-Parmer Instrument Co., Chicago, Ill.) was used to circulate solvent and hot water through the extractor. A metal screen with two filter papers (Whatman No. 2, Whatman International, Ltd., Maidstone, U.K.) on top was placed at the bottom of the extraction chamber to support the DDG particle bed during extraction. The main advantages of the extraction system were: (1) heat and mass transfer were enhanced by circulating the solvent through the particle bed, (2) no filtration was required to separate solid particles from the miscella (hexane and lipid mixture) after extraction, (3) the extraction temperature could be lower than the boiling point of the hexane to prevent thermal damage of heat sensitive extracts, and (4) the system had a continuous character as the miscella was released out of the system and fresh solvent added to the system during extraction.

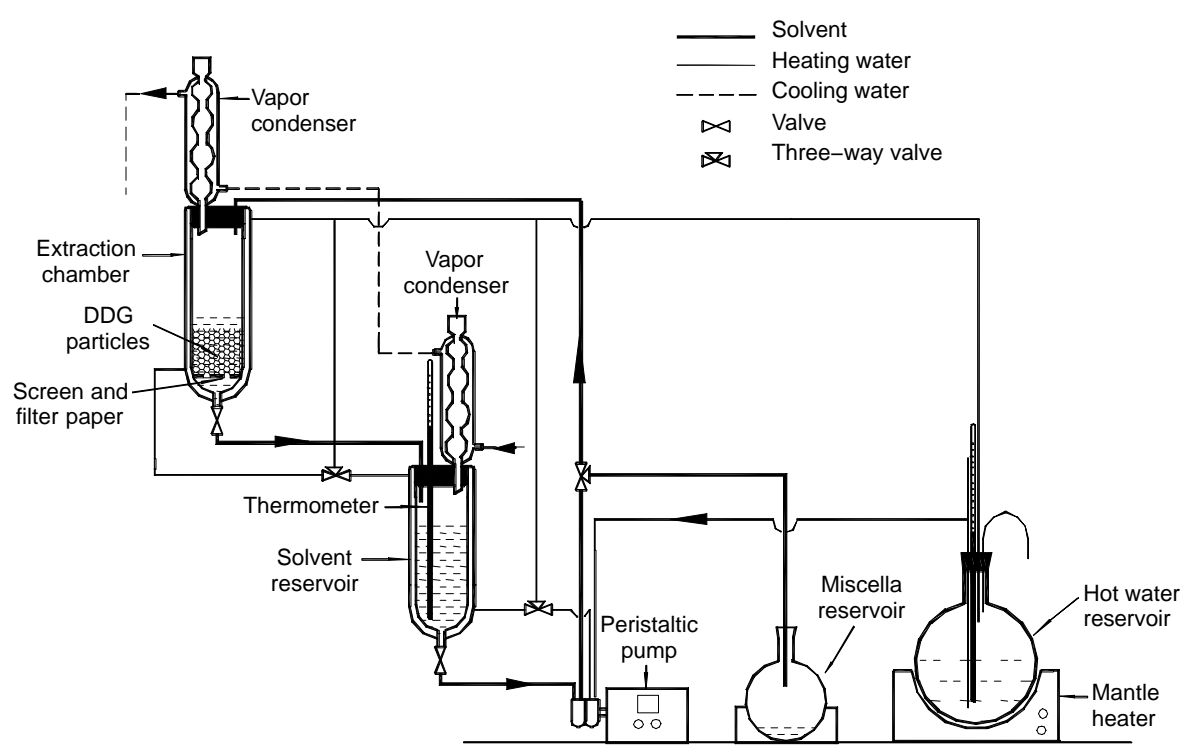

Figure 1. Diagram of bench-scale solvent extractor used for recirculation of hexane during extraction of lipids from grain sorghum DDG. 
Because the void space in a DDG particle bed retains an amount of solvent, the minimum solvent to solid ratio (mL:g) should be greater than one to allow for circulation of the solvent through the porous DDG particle bed. Samples of $100 \mathrm{~g}$ of DDG were placed in the extraction chamber and $200,300,400$, or $500 \mathrm{~mL}$ of hexane were placed in the solvent reservoir to form different ratios of solvent to solid (from 2:1 to $5: 1)$. The hexane and DDG bed were preheated to a set extraction temperature by circulating hot water through the outer jacket of the extraction chamber and solvent reservoir. After the DDG bed and hexane reached the target temperature, the hexane was directed to the extraction chamber by the pump. Once the solvent had covered the DDG bed, the valve at the outlet of the extraction chamber was adjusted to maintain the level of hexane right above the top of the DDG bed. The hexane was circulated between the extraction chamber and solvent reservoir by the pump. The extraction then proceeded for a given time. After extraction, the pump was stopped and the miscella was drained from the solvent reservoir to a flask. The DDG particle bed was rinsed with $200 \mathrm{~mL}$ of hexane, which was also collected in the miscella flask. The miscella was then concentrated using a rotary evaporator (Buchi model R-200, Fisher Scientific) under vacuum at $40^{\circ} \mathrm{C}$. The concentrated miscella was transferred to a pre-massed glass dish and placed in a controlled-environment chamber at $40^{\circ} \mathrm{C}$ for conditioning until it reached constant mass. The mass of the DDG lipid that remained in the dish was determined. The lipid was transferred to a glass bottle, sealed in the bottle, and stored in a freezer at $-12^{\circ} \mathrm{C}$ for later composition analysis. All extractions were carried out in duplicate. Extractability of sorghum DDG lipids using the bench-scale extractor was calculated by dividing the lipid yields by the Soxhlet control yield at the corresponding moisture content times 100 percent.

\section{Characterization OF DDG LiPIDS}

Normal phase thin-layer chromatography (TLC) separations were conducted on analytical and preparative layers on glass plates covered with silica gel Si60. About $10 \mu \mathrm{L}$ of lipid extract from grain sorghum DDG was spotted on a TLC plate. For comparison, oily and waxy fractions of a sorghum kernel extract and lipid standards were also spotted. The sorghum kernel extract was prepared using the bench-scale extractor. The developing solvents were hexane/diethyl ether/acetic acid (85:15:2 by volume). Developed bands were visualized by dipping the plate in a solution of $10 \mathrm{~g}$ cupric sulfate dissolved in $100 \mathrm{~mL}$ of $8 \%$ phosphoric acid for $5 \mathrm{~s}$, dried for $5 \mathrm{~min}$, and heated in an oven at $150^{\circ} \mathrm{C}$ until the developed bands were charred (Bitman and Wood, 1982; Hwang et al., 2002c).

\section{Results AND Discussion}

\section{Particle Size Distribution and Moisture Contents of} SORGHUM DDG

The size of DDG particles is one factor that may affect the extraction yield and efficiency of DDG lipids. The particle size distribution of the DDG used in this study is shown in figure 2. Approximately $42 \%$ of the DDG materials were observed to have particle size between 0.50 and $0.85 \mathrm{~mm}$. The mass of particles bigger than $1.70 \mathrm{~mm}$ and smaller than $0.106 \mathrm{~mm}$ was about $5.0 \%$ and $0.5 \%$ of the total mass,

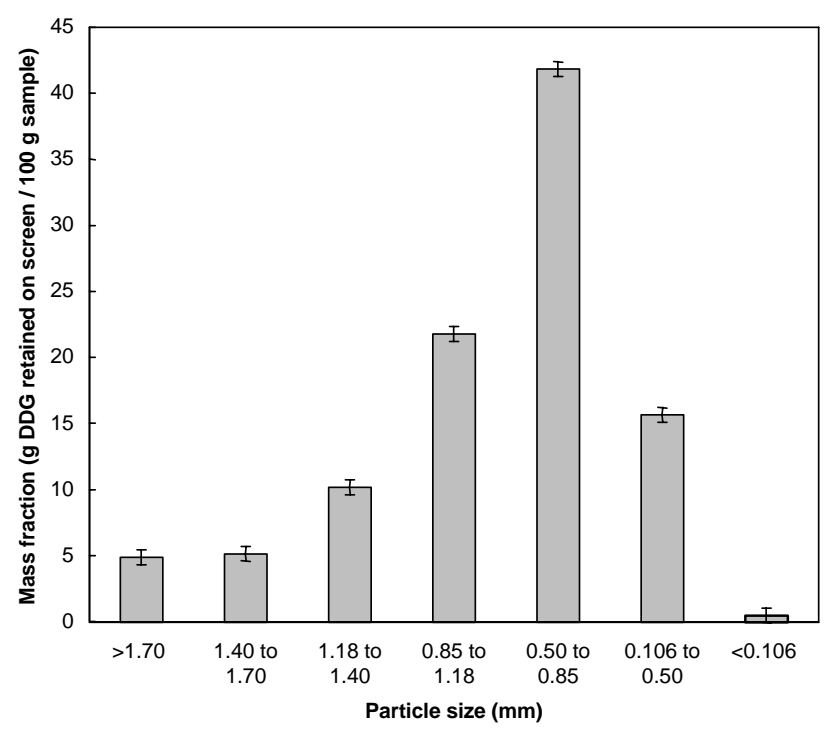

Figure 2. Characteristic particle size distribution in grain sorghum DDG samples.

respectively. The particle size distribution of sorghum DDG is similar to that of corn DDG (Rausch et al., 2005).

The moisture content of DDG is another factor that can affect the extraction efficiency. The moisture content of the stored grain sorghum DDG was 6.7\% (dry basis). For comparison of the effects of moisture content on extraction, the moisture content of the DDG was adjusted to three other levels $(2.1 \%, 12.0 \%$, and $17.4 \%)$ through drying or addition of distilled water. Moisture contents of adjusted DDG samples were checked by a moisture analyzer.

\section{QuANTIFication of LiPID ConTents AND CoMPositions}

The lipids extracted from grain sorghum DDG were determined over time using the Soxhlet extractor with hexane (with results shown in fig. 3). The lipid yields were $7.26 \%$ and $9.21 \%$ (mass of extracted lipid / mass of dried DDG $\times 100 \%$ ) after 0.5 and $6 \mathrm{~h}$ of extraction, respectively. Overall, the increase in lipid yield beyond $6 \mathrm{~h}$ was small, as yield at $12 \mathrm{~h}$

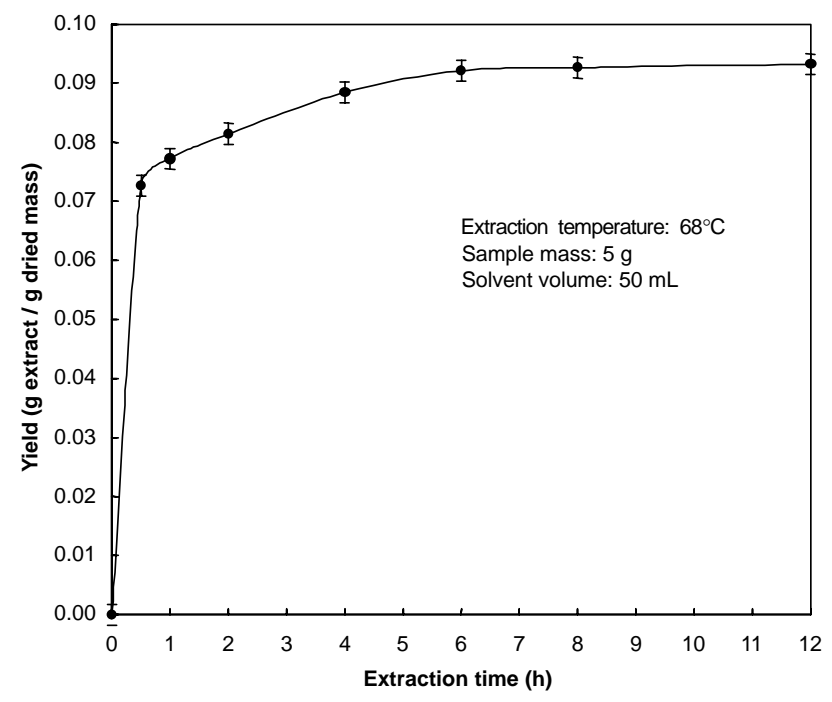

Figure 3. Yield of lipids (g lipid extract/g dried DDG mass) extracted from grain sorghum DDG (2.1\% moisture content, d.b.) with hexane over various extraction times. 


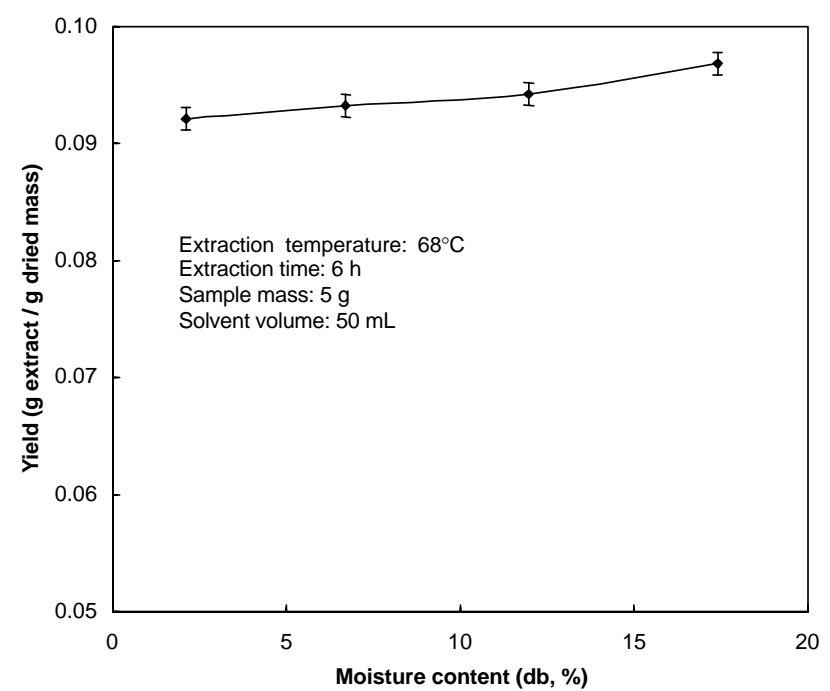

Figure 4. Yield of lipids ( $\mathrm{g}$ lipid extract / g dried DDG mass) extracted from grain sorghum DDG at various moisture contents with hexane.

was only $9.32 \%$. Therefore, after $6 \mathrm{~h}$ of extraction in the Soxhlet extractor with hexane, an extraction was assumed to reach equilibrium.

The effect of moisture content in the DDG on lipid yield is shown in figure 4. There was a slight increase in the lipid yield as the moisture contents increased from $2.1 \%$ to $17.4 \%$. The amounts shown in figure 4 were considered as the absolute control efficiencies of $100 \%$ for the extractable lipids from sorghum DDG for the corresponding moisture contents.

The effect of particle size of the DDG on the extracted lipid yield is shown in figure 5. The lipid yield from the DDG particles with a size between 0.5 and $0.85 \mathrm{~mm}$ was $9.90 \%$ of dried mass, while it was only $8.12 \%$ for particles larger than $1.18 \mathrm{~mm}$, compared with the value of $9.21 \%$ lipid in the initial DDG sample at $2.1 \%$ moisture content. Particle size of DDG can affect the heat and mass transfer between the solid and solvent during extraction. On one hand, the reduction of particle size can increase the surface area to volume ratio of a particle and thus increase the extraction yield. On the other hand, the DDG particles with different sizes may come from different locations, such as the germ, endosperm, and pericarp in a grain sorghum kernel, with different lipid contents during the grinding process. The lipid yield from the further ground DDG particles with a size between 0.5 and $0.85 \mathrm{~mm}$ was only $8.67 \%$, which is greater than that of the original large particles $(8.12 \%)$ but smaller than that of the particles in the DDG with the same size $(9.90 \%)$. Therefore, both the particle size and the original source of DDG particles from within the kernel have effects on the extracted lipid yield.

The TLC analysis of grain sorghum DDG extract is shown in figure 6. The lipids extracted from DDG were composed of $96.7 \%(\mathrm{w} / \mathrm{w})$ oily fraction and $3.3 \%$ waxy fraction, while $75 \%$ of the extract from whole sorghum kernels was waxy and the other $25 \%$ was oily fraction. The components of the extracted DDG lipids included triacylglycerols, fatty acids, fatty alcohols, fatty aldehydes, free sterols, wax esters, and steryl esters. Comparing the TLC bands of DDG lipids with the TLC bands of oily and waxy fractions of whole-grain sorghum kernel extract, the waxy fraction is composed mainly of fatty acids, fatty aldehydes, fatty alcohols, and

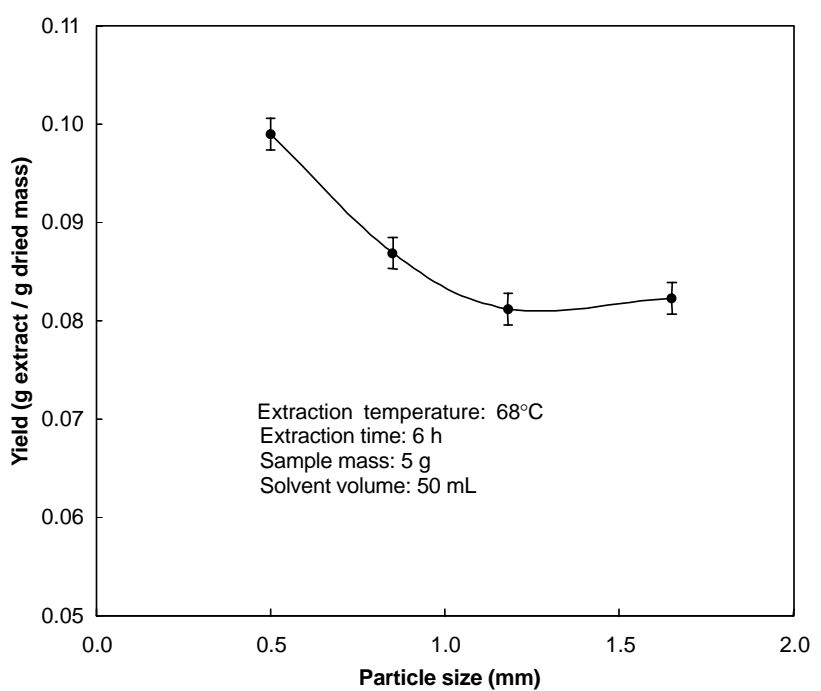

Figure 5. Yield of lipids (g lipid extract / $g$ dried DDG mass) extracted from grain sorghum DDG (2.1\% moisture content, d.b.) particles of various sizes.

esters, while other components such as triacylglycerols, sterols, and part of the fatty acids are in the oily fraction of DDG lipids. The waxy fraction from grain sorghum is a potential source of natural wax with properties similar to carnauba wax (Hwang et al., 2002a). The unsaturated fatty acids and sterols including phytosterols are effective in lowering total and low-density lipoprotein cholesterol in blood by inhibiting the absorption of cholesterols in the small intestine (Bernardo-Gil et al., 2002). The triacylglycerols are similar in composition to other regular vegetable oils. These lipid components may be further refined and used as food and pharmaceutical ingredients.

\section{Effects of Operating Parameters on Extractability}

The extractability (percent ratio of extracted lipid yield to the total lipid content in the DDG) increased with the increase of extraction time, as shown in figure 7 for the solvent to solid

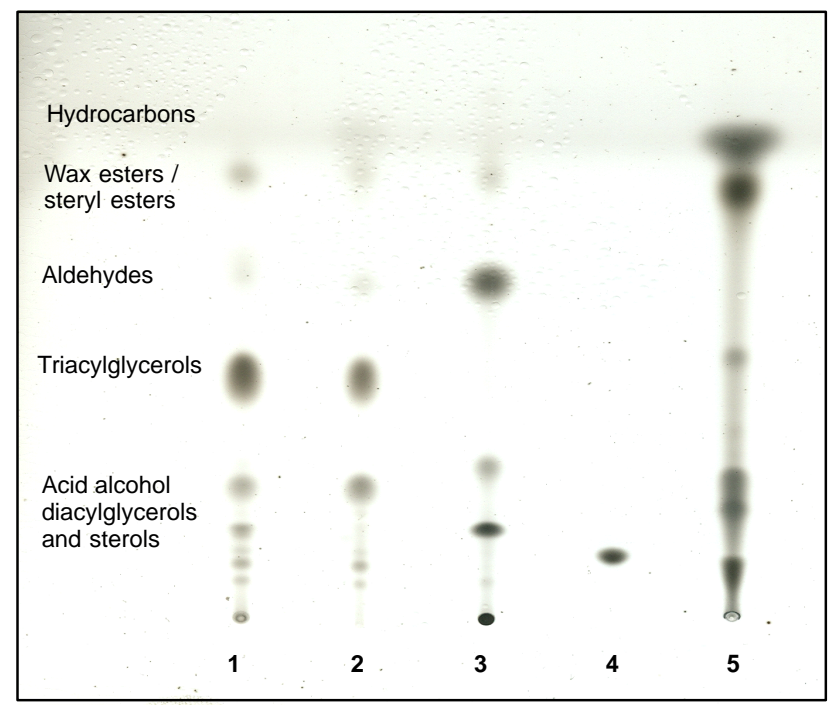

Figure 6. TLC plate spotted with sorghum DDG and kernel extracts developed in hexane/diethyl ether/acetic acid $(85: 15: 2)$ at $150^{\circ} \mathrm{C}$ for $5 \mathrm{~min}$ : (1) DDG extract, (2) oily fraction of kernel extract, (3) waxy fraction of kernel extract, (4) standard I: $\beta$-sitosterol, (5) standard II: lignoceryl lignocerate, cholesterol, n-octacosane, triarachidin, diarachidin, cholesterol behenate, monoarachidin, and lignoceric acid. 


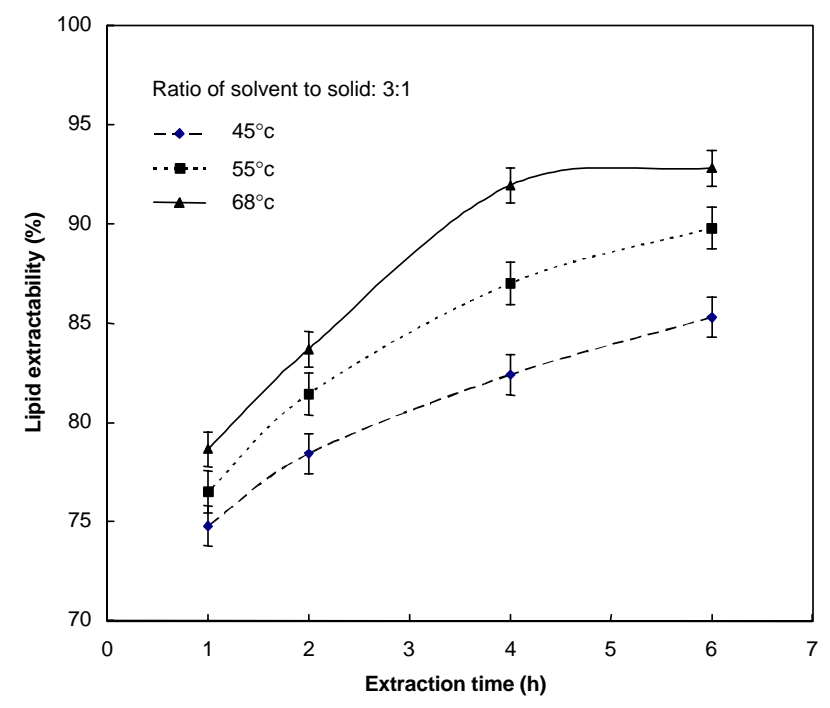

Figure 7. Extractability of lipids from grain sorghum DDG (2.1\% moisture content, d.b.) over various extraction times using hexane at three different temperatures.

ratio of $3: 1$. The higher the extraction temperature was, the shorter the extraction time was to reach the extraction equilibrium. For example, at the extraction temperature of $68^{\circ} \mathrm{C}$ (the boiling point of $\mathrm{n}$-hexane), the extractability was $78.6 \%$ after $1 \mathrm{~h}$ extraction and it became $92.0 \%$ after $4 \mathrm{~h}$ extraction. However, there was no apparent increase with further increase of extraction time beyond $4 \mathrm{~h}$. Therefore, as the extraction temperature approaches the boiling point of n-hexane, extraction equilibrium can be reached near $4 \mathrm{~h}$ of extraction, while more time would be needed to reach the extraction equilibrium at lower extraction temperatures.

The effect of solvent to solid ratio on the extractability is shown in figure 8 . The extractability increased when the solvent to solid ratio was increased from $2: 1$ to $5: 1$. However, the effects of solvent to solid ratio on the extractability became smaller as the extraction temperature was increased from $45^{\circ} \mathrm{C}$ to $68^{\circ} \mathrm{C}$. At the extraction temperature of $68^{\circ} \mathrm{C}$, the extractability was $89.5 \%$ and $92.8 \%$ if the solvent to solid ratios were 2:1 and 3:1, respectively. There was apparent increase in lipid yield with further increases in solvent to solid ratios. Therefore, if the extraction temperature is near the boiling point of n-hexane, a solvent to solid ratio of $3: 1$ could be chosen to achieve a high level of extractability. For lower extraction temperatures, the solvent to solid rations would have to be above 3:1 to achieve comparable extractability.

The effects of extraction temperature on extractability can also be seen in figure 8 . Extractability increased when the extraction temperature was increased from $45^{\circ} \mathrm{C}$ to the boiling point of $n$-hexane at $68^{\circ} \mathrm{C}$. However, the effects of extraction temperature on the extractability became smaller when the solvent to solid ratio was increased. When the extraction temperature was increased from $45^{\circ} \mathrm{C}$ to $68^{\circ} \mathrm{C}$, the extractability was increased from $80.6 \%$ to $89.5 \%$ if the solvent to solid ratio was $2: 1$, while it was increased only from $91.0 \%$ to $94.5 \%$ if the ratio was $5: 1$. If the extraction temperature must be low to prevent any damage to thermal sensitive lipid components, the solvent to solid ratio should meanwhile be increased to achieve a high extraction yield.

As shown above, the extractability of DDG lipids for the bench-scale recirculated extraction system increased with

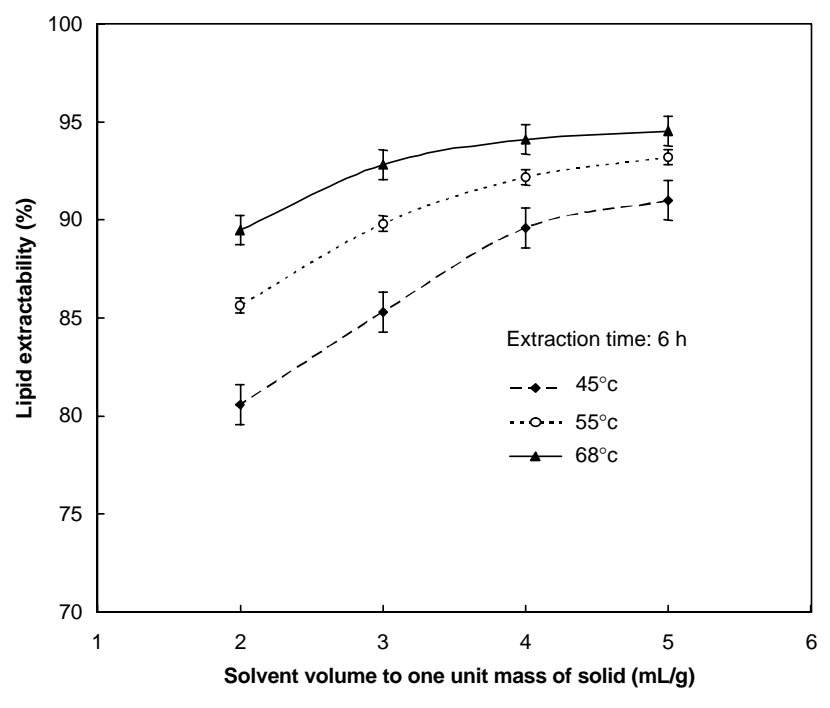

Figure 8. Extractability of lipids from grain sorghum DDG (2.1\% moisture content, d.b.) over various ratios of solvent volume to solid mass using hexane at three different temperatures.

increases of the solvent to solid ratio, extraction temperature, and extraction time. Under various experimental conditions including solvent to solid ratio $(2: 1$ to $5: 1)$, extraction temperature $\left(45^{\circ} \mathrm{C}, 55^{\circ} \mathrm{C}\right.$, and $\left.68^{\circ} \mathrm{C}\right)$, and extraction time $(1$ to $6 \mathrm{~h})$, the minimum extractability was $70.3 \%$ when a solvent to solid ratio of $2: 1$, extraction temperature of $45^{\circ} \mathrm{C}$, and extraction time of $1 \mathrm{~h}$ were chosen. Maximum extractability of $94.5 \%$ was observed at a solvent to solid ratio of $5: 1$, extraction temperature of $68^{\circ} \mathrm{C}$, and extraction time of $6 \mathrm{~h}$. When the extraction temperature was $68^{\circ} \mathrm{C}$ (the boiling point of n-hexane), the extractability was $92 \%$ for the solvent to solid ratio of 2:1 and extraction time of $4 \mathrm{~h}$. Extractability will not likely be further increased by increasing the solvent to solid ratio or the extraction time. If the extraction temperature must be decreased to prevent damage to thermal-sensitive lipid components, the solvent to solid ratio and extraction time should be increased with the decrease of extraction temperature to achieve a high extraction yield. An optimal extraction temperature should further be justified by the quality of the extracted lipids.

\section{Conclusions}

The lipid content in stored grain sorghum DDG with a moisture content of $6.7 \%$ (d.b.) was $9.32 \%$ of the dried mass determined by Soxhlet extraction with n-hexane. The components of the extracted DDG lipid included triacylglycerols, fatty acids, fatty alcohols, fatty aldehydes, free sterols, wax esters, and steryl esters. Among those components, the majority was triacylglycerols, which can be refined and used as vegetable oils.

At extraction temperatures near the boiling point of n-hexane, the solvent to solid ratio can be $3: 1$ with an extraction time of $4 \mathrm{~h}$ to achieve maximum lipid yield. There is no apparent increase in extraction yield with further increase of the solvent to solid ratio or extraction time.

The extractability of DDG lipids ranged from $70.3 \%$ to $94.5 \%$ under various experimental conditions, which included solvent to solid ratio $(2: 1$ to $5: 1)$, extraction temperature $\left(45^{\circ} \mathrm{C}, 55^{\circ} \mathrm{C}, 68^{\circ} \mathrm{C}\right)$, and extraction time (1 to $\left.6 \mathrm{~h}\right)$. 


\section{ACKNOWLEDGMENTS}

This research was supported in part by funds provided by the National Research Initiative of the USDA Cooperative State Research, Education and Extension Service (Grant No. 2004-35503-14824), by the Regional Research Centers Program of the Korean Ministry of Education and Human Resources Development through the Center for Healthcare Technology Development, and through the Hatch Act.

\section{REFERENCES}

Bernardo-Gil, M. G., J. Grenha, J. Santos, and P. Cardoso. 2002. Supercritical fluid extraction and characterization of oil from hazelnut. European J. Lipid Sci. Tech. 104(7): 402-409.

Bitman, J., and D. L. Wood. 1982. An improved copper reagent for quantitative densitometri thin-layer chromatography of lipids. $J$. Liquid Chromatogr. 5(6): 1155-1162.

Hwang, K. T., S. L. Cuppett, C. L. Weller, and M. A. Hanna. 2002a. Properties, composition, and analysis of grain sorghum wax. $J$. American Oil Chem. Soc. 79: 521-527.

Hwang, K. T., S. L. Cuppett, C. L. Weller, and M. A. Hanna. 2002b. HPLC of grain sorghum wax classes highlighting separation of aldehydes from wax esters and steryl esters. J. Sep. Sci. 25(9): 619-623.

Hwang, K. T., S. L. Cuppett, C. L. Weller, M. A. Hanna, and R. K. Shoemaker. 2002c. Aldehydes in grain sorghum wax. $J$. American Oil Chem. Soc. 79: 529-533.

Kaufmann, B., and P. Christen. 2002. Recent extraction techniques for natural products: Microwave-assisted extraction and pressurized solvent extraction. Phytochem. Anal. 13(2): 105-113.
Lang, Q., and C. M. Wai. 2001. Supercritical fluid extraction in herbal and natural product studies - A practical review. Talanta 53(4): 771-782.

Luque de Castro, M. D., and L. E. Garcia-Ayuso. 1998. Soxhlet extraction of solid materials: An outdated technique with a promising innovative future. Anal. Chimica Acta 369(1-2): $1-10$.

Maestri, D. W., D. O. Labuckas, A. L. Lamarque, J. A. Zygadlo, N. R. Grosso, M. J. Martinez, and C. A. Guzman. 1996. Proximate composition and seed lipid components of sorghum cultivars from Argentina. J. Sci. Food Agric. 70(3): 334-336.

Rausch, K. D., R. L. Belyea, M. R. Ellersieck, V. Singh, D. B. Johnston, and M. E. Tumbleson. 2005. Particle size distributions of ground corn and DDGS from dry grind processing. Trans. ASAE 48(1): 273-277.

Schmidt, B. J. 2002. A comparison of techniques for the extraction of waxes from grain sorghum. MS thesis. Lincoln, Neb.: University of Nebraska-Lincoln, Department of Biological Systems Engineering.

Singh, V., R. A. Moreau, and K. B. Hicks. 2003. Yield and phytosterol composition of oil extracted from grain sorghum and its wet-milled fractions. Cereal Chem. 80(2): 126-129.

Vinatoru, M. 2001. An overview of the ultrasonically assisted extraction of bioactive principles from herbs. Ultrason. Sonochem. 8(3): 303-313.

Zarnowski, R., and Y. Suzuki. 2004. Expedient Soxhlet extraction of resorcinolic lipids from wheat grains. J. Food Compos. Anal. 17(5): 649-664. 